\title{
Vision and visual variation in the peacock blenny
}

\author{
E. M. White*†, D. M. Gonçalvesł, J. C. Partridge* and \\ R. F. Oliveirat
}

* School of Biological Sciences, University of Bristol, Woodland Road, Bristol, BS8

IUG, U.K. and \$Unidade de Investigação em Eco-Etologia, Instituto Superior de Psicologia Aplicada (ISPA), Rua Jardim do Tabaco 34, 1049-041 Lisboa, Portugal

(Received 24 March 2003, Accepted 14 April 2004)

\begin{abstract}
Microspectrophotometry (MSP) revealed the presence of a rod and at least two cone classes (mid- and long-wavelength sensitive) in the intertidal peacock blenny Salaria pavo. Both rhodopsin and porphyropsin based visual pigments were found in all fish, together with high individual variation in chromophore ratio. The three morphs (females, males and sneaker males) differed in their spectral sensitivities (as measured with the optomotor response) with sneakers having higher sensitivity at long-wavelengths than either males or females. This longwave displacement of peak sensitivity could be due elevated proportions of porphyropsin visual pigments in the sneakers' retinae. The lenses of all morphs exhibited a short-wavelength cut-off and an unusual layer of carotenoid was found behind the retinal pigment epithelium and in the outer segments of some cones. These screening pigments could serve a photo-protective role or to improve visual contrast. No short-wave photoreceptors were located using MSP. This indicates that this cone class may be absent or present at very low numbers in the retina. This is the first in depth study of the visual system of a blenniid fish and indicates potential within-species visual variation that may be related to the species' habitat and morph-specific behavioural requirements.

(C) 2004 The Fisheries Society of the British Isles
\end{abstract}

Key words: intertidal fishes; light environment; microspectrophotometry; optomotor response; visual variation.

\section{INTRODUCTION}

Both the photic environment and the visual tasks animals have to perform produce selective forces acting upon visual systems (Lythgoe, 1972; McFarland \& Munz, 1975; Levine \& MacNichol, 1979; Partridge \& Cummings, 1999). In some species of fishes, spectral sensitivity has been reported to vary seasonally (e.g. rudd Scardinius erythrophthalmus (L.); Whitmore \& Bowmaker, 1989) or during their ontogenetic development (Beaudet \& Hawryshyn, 1999). Such shifts can be effected either by changes in the expression of genes encoding the protein (opsin) component of a visual pigment, or by changes in the chromophore moiety which, in fishes, is either a derivative of vitamin $A_{1}$ or

†Author to whom correspondence should be addressed. Tel.: +4401179287591; fax: +4401179257374; email: elizabeth.white@bristol.ac.uk 
vitamin $A_{2}$. Visual pigments based on these chromophores are rhodopsins and porphyropsins respectively. Porphyropsin visual pigments have broader absorption spectra and long-wave displaced absorption maxima compared with their rhodopsin analogues (i.e. the rhodopsin based on the same opsin). Many species show shifts in the spectral absorptions of their visual pigments with age [(e.g. pollack Pollachius pollachius (L.), Shand et al., 1988; goatfish Upeneus tragula Richardson, Shand, 1993; white sturgeon Acipenser transmontanus Richardson, Loew \& Sillman, 1993; black bream Acanthopagarus butcheri (Munto), Shand et al., 2001)], or the loss or gain of a whole class of receptor [(e.g. brown trout Salmo trutta L., Bowmaker \& Kunz, 1987; rainbow trout Oncorhynchus mykiss (Walbaum), Hawryshyn et al., 1989; perch Perca flavescens (Mitchill), Loew \& Wahl, 1991; Pacific salmon Oncorhynchus sp., Beaudet et al., 1997)]. Such shifts will have an effect on the spectral sensitivity of the animals concerned and are often correlated with changes in light environment experienced by the animals whether due to seasonal changes in the environment or changes in habitat use by the animals. Differences in visual pigment complement in fish species that are phylogenetically close have been shown to relate to differences in their microhabitats' light environment (Cummings \& Partridge, 2001). It can thus be hypothesized that shifts in spectral sensitivity are physiological adaptations to different visual tasks (Partridge \& Cummings, 1999).

Although visual pigments have been investigated in a wide range of fishes from deep-sea to shallow-water species (Bowmaker, 1990, 1996) such information on intertidal fishes is relatively scarce (Blennius pholis L., Loew \& Lythgoe, 1978; Lythgoe \& Partridge, 1989; Gobius paganellus L., Lythgoe \& Partridge, 1989). The shallow intertidal is notable as a habitat subject to changes in photic environment associated with season and weather conditions and, as with other aspects of their physiology, intertidal fishes are thus likely to have visual systems capable of rapid physiological adaptation to changing visual conditions. Such adaptations include shifts in visual pigments and spectral sensitivity. In the present study, the spectral absorptions of the retinal photoreceptors of an intertidal fish, the peacock blenny Salaria pavo (Risso), was measured using microspectrophotometry (MSP) and the possibility of within-species variation, explored. The MSP data are related to behavioural spectral sensitivity measured using the optomotor response. The optomotor test is a psychophysical approach that exploits the natural tendency of fishes to stay stationary in a moving body of water by fixing an image of their surroundings on the retina and swimming in order to stay stationary with respect to those surroundings. The method can be used to construct action spectra and has been used previously for other fish species (Cronly-Dillon \& Muntz, 1965; Schaerer \& Neumeyer, 1996; Anstis et al., 1998). Using these techniques specific investigation was made of three morphs of $S$. pavo that explore different microhabitats, with differing light environments, and that need to perform different visual tasks.

The peacock blenny is native to the Mediterranean and Atlantic coast, from Morocco to southern France (Zander, 1986). It exhibits a strong sexual dimorphism and dichromatism with males being larger than females and having a well-developed yellowish head crest (Papaconstantinou, 1979; Patzner et al., 1986). Both sexes have blue dots and stripes in the head and body and an iridescent blue eyespot behind the eye. Females are yellowish-green with dark 
vertical bars, which are enhanced during their nuptial colouration displays (Abel, 1993; Almada et al., 1995), while nesting males are olive-green with brown vertical bars on the flanks and head (Abel, 1993). The mating system is promiscuous and males guard and care for the eggs (Patzner et al., 1986).

In a mudflat area in the Ria Formosa (southern Portugal), where fish were collected for this study, there is a scarcity of appropriate nest sites and males nest in bricks used by clam culturists to delimit the frontiers of their fields. The bricks stay emerged for some hours during low tide and fish remain inside the moist brick holes. The scarcity of nests promotes two notable features of this mating system: (1) only larger males are able to defend nests, which promotes a reversal of the sex-roles, with females competing for males and actively courting them (Almada et al., 1995); (2) smaller and younger males are unable to defend nests so act as sneakers, imitating the females' behaviour and morphology to approach the nesting males, and try to achieve parasitic fertilizations of the eggs (Gonçalves et al., 1996). The males' alternative reproductive tactics are sequential, as sneakers develop into large nesting males (henceforth referred to as 'males') from one breeding season to the next (D. Gonçalves, T. Fagundes \& R. Oliveira, unpubl. data).

During the breeding season the visual tasks that males, females and sneakers have to perform are different. Males seldom leave the nest, even to feed, in order to avoid losing the site to a competitor. Males therefore assess females (and sneakers) as visual targets visualized against the water background. Females feed in seagrass beds and approach bricks to assess males against the brick background. Sneakers also feed in seagrass beds but spend most of the time associating with successful nesting males and waiting for spawning episodes to occur (Gonçalves et al., 2003). These distinct and critical visual tasks are very likely to be best tackled with visual systems having different spectral sensitivities (Lythgoe \& Partridge, 1989, 1991; Partridge \& Cummings, 1999). Whether the different morphs have different spectral sensitivities, as their differing visual tasks might suggest, was investigated.

\section{MATERIALS AND METHODS}

\section{PREPARATION AND PRESERVATION OF EYES, RETINAL TISSUE AND LENSES}

Fish used in this study were collected at the Ria Formosa Nature Park, Portugal, during the breeding season (June to July). Five fish, comprising two males, one female and two sneakers, were transported in oxygen-saturated water to the Instituto Superior de Psicologia Aplicada (ISPA), Lisbon. They were dark adapted for a period of $>20 \mathrm{~h}$, anaesthetized with $0.1 \%$ MS-222 (sodium methanesulphonate, c. 0.05\%; Jolly et al., 1972) to cessation of opercular movement and, under dim red illumination from a head torch, killed by decapitation and destruction of the central nervous system. Eyes were removed under dim red illumination with the aid of a magnifying glass. For each fish, one eye was frozen whole in $0.5 \mathrm{ml}$ PIPES buffered saline (PIPES $20 \mathrm{mM}, \mathrm{NaCl} 180 \mathrm{mM}$, $\left.\mathrm{KCL} 19 \mathrm{mM}, \mathrm{MgCl}_{2} 1 \mathrm{mM}, \mathrm{CaCl}_{2} 1 \mathrm{mM} ; \mathrm{mOsm} \mathrm{Kg}^{-1} 425: \mathrm{pH} 6 \cdot 5\right)$ in a $1.5 \mathrm{ml}$ Eppendorf tube, for use in visual pigment extraction. The other eye was preserved for MSP using a 'slow freeze' method of preservation (Fritches et al., 2000; Cummings \& Partridge, 2001). The eye was dissected under dim red light and the retina removed to 
a coverslip with a small drop of PIPES saline with 10\% Dextran 260000 MW and 15\% Dextran $12000 \mathrm{MW}$, which act as cryoprotectants. The retina was teased apart using fine entomological needles to detach individual photoreceptors from other retinal tissue. The preparation was covered with a coverslip and squeezed gently between filter papers to expel excess liquid. The preparation was sealed using black nail varnish and placed in a light-tight aluminium tube. Preparations were maintained at $5^{\circ} \mathrm{C}$ for $1 \mathrm{~h}$ and subsequently transferred to an $-80^{\circ} \mathrm{C}$ freezer for storage in Lisbon. Samples were transferred to Bristol on dry-ice where they were maintained at $-80^{\circ} \mathrm{C}$, until use.

Two males, three females and two sneakers were transported live to Bristol, in oxygensaturated water for fresh retinal and lens examination. They were housed in aquaria under 'full spectrum', daylight simulating light conditions (True-Lite, Duro-Test, U.S.A.) on a $12 \mathrm{~L}: 12 \mathrm{D}$ photoperiod, and maintained in the laboratory until use (one to 12 weeks). Prior to use, each fish was dark-adapted overnight for a period $>12 \mathrm{~h}$. Fish were collected under dim red light from a head-torch and placed into a lightproof canister for transfer to the darkroom. They were anaesthetized with an overdose of MS-222 and killed by humane methods in accordance with U.K. Home Office legislation.

Eyes were removed and divided along the middle line with the aid of an infra-red image converter (FJW Optical Systems Inc. Find-R-Scope) attached to a low-power microscope. Each eye was opened, the lens removed and the eye cup transferred to a Petri dish of saline (Dulbecco 'A' phosphate buffered saline solution, diluted to $425 \mathrm{mOsmol} \mathrm{kg}^{-1}$, Oxoid Ltd) for subsequent measurement of lens transmission. For MSP analysis, small sections of retina were placed on a coverslip and prepared as above.

\section{MSP MEASUREMENTS}

The microspectrophotometer used in this study is a computer-controlled, wavelengthscanning instrument of single-beam design (Hart et al., 1998). Absorbance spectra from individual rods and cone outer segments were measured from cells from five frozen and seven fresh pairs of retinae from four males, four females and four sneakers, using methodologies fully described elsewhere (Hart et al., 1998). For each cell, sample and baseline scans were measured. Following scanning, each cell was bleached with white light from the monochromator for $2 \mathrm{~min}$ and a further scan made post-bleach. This postbleach scan was then subtracted from the pre-bleach average in order to produce a difference spectrum for each cell and to confirm photolability.

Data were analysed using a Microsoft Excel macro as described by Hart et al. (1998) using a 21 point unweighted running average and analysed by fitting the rhodopsin template of Govardovskii et al. (2000). The $\lambda_{\max }$ was determined using the methods of MacNichol (1986) modified by Govardovskii et al. (2000), by fitting a least-squares regression line to the long-wave data between 70 and $30 \%$ normalized absorbance. The short-wave region was excluded from template-fitting, as this region is most susceptible to photo-product build-up. Only scans that fitted predetermined selection criteria were accepted, specifically: (1) if the template data fell within the noise of the absorbance data between $80 \%$ short wave and $20 \%$ long wave absorbance; (2) if absorbance spectra were flat in the long-wave region following the point of zero absorbance; (3) if absorbance spectra were free from obvious distortions (Levine \& MacNichol, 1985); (4) if photolability was proved through bleaching.

In total, 1870 scans were made and 582 were accepted, representing measurements from 230 cells. All scans were initially best-fitted by a rhodopsin ( $\mathrm{A}_{1}$-based) visual pigment template (Govardovskii et al., 2000) for preliminary analysis. In all fish, however, unusually high variation in the spectral positions of rod and cone pigment $\lambda_{\max }$ values occurred, and there was variation in bandwidth, suggestive of a mixed chromophore (Bridges, 1972). Due to this variation, the wavelength corresponding to maximum absorbance, the running average, 'over-the-top' (OTT) $\lambda_{\max }$ of the normalized absorbance data, which makes no assumptions about visual pigment chromophore was used. 


\section{VISUAL PIGMENT EXTRACTION AND PARTIAL BLEACHING}

Extraction of visual pigments was carried out under dim red light from a head-torch and following the methods of Douglas et al. (1999). Individual retinae were homogenized in $1 \mathrm{ml}$ PIPES buffered saline in a $1.5 \mathrm{ml}$ microcentrifuge tube. The detergent, $\mathrm{n}$-dodecyl $\beta$-D-maltoside $(200 \mathrm{mM})$ was added to the homogenate at a ratio of $100 \mu \mathrm{ml}^{-1}$. The samples were then mixed for $1 \mathrm{~h}$ on a rotator wheel $(4 \mathrm{rpm})$ at room temperature, then centrifuged at $4^{\circ} \mathrm{C}$ and $23142 \mathrm{~g}$ for $10 \mathrm{~min}$. The supernatant was drawn off, decanted into a quartz cuvette and scanned in a Shimadzu UV2102 PC UV-VIS scanning spectrophotometer (Shimadzu Scientific Instruments Inc., Columbia, U.S.A.). Following this initial scan, $50 \mu$ of hydroxylamine $(\mathrm{pH} 6.5)$ was added per ml supernatant, mixed by inversion and left to stand for at least $1 \mathrm{~h}$. The sample was then scanned a second time.

Partial bleaching of the extract (Knowles \& Dartnall, 1977) was carried out using a light source comprising B-40 narrow band interference filters (Balzers, Liechtenstein) in front of a $4.5 \mathrm{~V}$ tungsten bulb. These filters have a bandwidth (measured as full width at half maximum transmission) of $c .15 \mathrm{~nm}$ and median wavelengths of transmission of 713 , $674,660,648,602,578,559,552$ and $506 \mathrm{~nm}$ (corresponding to their nominal wavelengths of maximum transmission of 708, 670, 656, 645, 595, 575, 560, 543 and $501 \mathrm{~nm}$ ). For bleaching purposes, the sliding lid of the Shimadzu spectrophotometer was opened and the monochromatic light source placed close to the sample. Initially the sample was exposed to monochromatic long-wavelength light $(713 \mathrm{~nm})$ and then re-scanned. This was then followed by further bleaches and scans at decreasing wavelengths. All absorption spectra were 'zeroed' at $700 \mathrm{~nm}$ prior to measurement.

Data were combined to create average absorbance curves from four independent extracts for each retina. Difference spectra were then constructed using the curves obtained at various stages of the partial bleaching process. These revealed the visual pigments as they bleached. For each difference spectrum, the $\lambda_{\max }$ of the visual pigments were determined by normalizing the data and fitting visual pigment templates (Govardovskii et al., 2000). Shifts in $\lambda_{\max }$ from long- to short-wavelengths with successive bleaches were taken to indicate the presence of a second visual pigment (Knowles \& Dartnall, 1977).

Visual pigment extraction was carried out on six frozen whole-eye preparations. Very low densities of rod visual pigment, however, were detected, due to the very small size of the eyes used. Consequently, data had a low signal to noise ratio and only four of the partial bleaching experiments produced useable results (i.e. a bleaching component was detectable). These were averaged to increase signal to noise in the overall sample.

\section{TRANSMISSION OF OCULAR MEDIA}

The transmission properties of 18 ocular lenses from four females, three males and three sneakers were measured using a Shimadzu UV2101PC UV-VIS scanning spectrophotometer fitted with a Shimadzu ISR-260 integrating sphere (Shimadzu Scientific Instruments Inc., Columbia, U.S.A.). Lens holders and references were constructed from identical $1 \times 1 \times 5 \mathrm{~cm}$ aluminium billets into which 1 or $1.5 \mathrm{~mm}$ diameter holes were drilled to hold the lens and block transmission of all other light. The aluminium billets were placed into quartz cuvettes and positioned in the sample holder in front of the integrating sphere. Initially, a base-line measurement was made using two identical, empty billets placed in the sample and reference positions. Following base-lining, an individual lens was carefully placed into the appropriate sized sample billet (such that the lens filled the hole), replaced in the cuvette and a slow scan from 300 to $700 \mathrm{~nm}$ was made. All scans were acquired using Shimadzu software (UVPC personal Spectroscopy Software, version 3.51, Shimadzu Scientific Instruments Inc., Columbia, U.S.A.). For ease of comparison, all lens data were normalized to an absorbance of zero $(100 \%$ transmission) at $700 \mathrm{~nm}$, following the methods of Thorpe et al. (1993).

The transmission of the cornea was also measured using fresh tissue from one fish. The corneas were removed, placed onto a microscope slide with a drop of PIPES buffered saline and measured using a CCD spectrophotometer as described below for retinal sectioning. 


\section{OCULAR SECTIONING AND ABSORBANCE MEASUREMENTS}

Vertical sections were made through the eye of a freshly killed female peacock blenny. The fish was killed using methods detailed above, and one eye removed and frozen in 'optimum cutting temperature' compound (OCT compound, B.D.H. Laboratory Supplies, U.K.) with cryospray (Cryospray 134, Bright Instrument Co., U.K.). Sections ( $20 \mu \mathrm{m}$ thick) were made within a cryostat in a vertical plane sequentially from the anterior to posterior of the body. Each section was placed onto a microscope slide with a drop of glycerol. A coverslip was placed on top and sealed using clear nail varnish. Sections were frozen at $-80^{\circ} \mathrm{C}$ until use. Absorbance spectra $(350-800 \mathrm{~nm})$ of small areas of the slide were made using a CCD spectrophotometer (USB2000, Ocean Optics, U.S.A.) via a $500 \mu \mathrm{m}$ diameter, single core fibre optic to a camera body mounted on the camera port of an Olympus BH-B compound microscope. The fibre optic projects to $5 \mu \mathrm{m}$ diameter in the plane of the specimen using a $\times 40$ objective. Recordings were made using Ocean Optics OOIIBASE32 software and measuring illumination was provided using the microscope's in-built light source.

Colour photographs from around the eye were also made using a Nikon F90x camera mounted on the Olympus microscope.

\section{THE OPTOMOTOR RESPONSE}

Eight males, eight females and eight sneakers were captured at the Ria Formosa and transferred to aquaria in Lisbon where they were maintained in 801 holding tanks, under 16L : 12D photoperiod. Fish were weighed and measured for identification purposes. The apparatus (Fig. 1) consisted of an $18 \mathrm{~cm}$ diameter ( $8 \mathrm{~cm}$ deep) cylindrical glass aquarium suspended from a frame by fine nylon thread, and comprising glass sides and an opaque base. The cylindrical tank was surrounded by an outer, cardboard cylinder, $30 \mathrm{~cm}$ diameter and marked in the inner side with 48 alternating black and white vertical stripes $(2 \mathrm{~cm}$ width). This drum was rotated clockwise $(\mathrm{CW})$ or anti-clockwise $(\mathrm{CCW})$ by an electric motor at a constant speed of $17 \mathrm{rpm}$. The drum was illuminated by means of a slide projector. Even illumination was provided across the drum by reflecting the projector light from a convex mirror, placed above the cylindrical aquarium. The framework

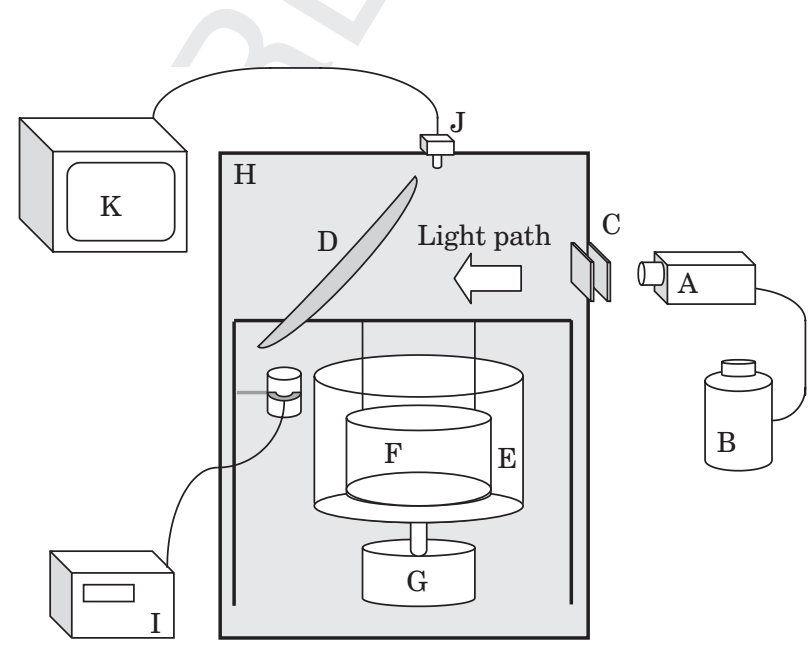

FIG. 1. Diagrammatic view of optomotor response apparatus. A, slide projector controlled by variable voltage source B; C, interference and heat filters; D, convex mirror; E, outer revolving drum lined with black and white stripes; F, circular glass tank suspended within drum; G, bi-directional electric motor; H, metal frame covered in blackout fabric; I, light meter; J, infra-red camera; and K, video monitor. 
supporting the drum was screened with blackout fabric to block light from everywhere but the light source. Monochromatic light was provided by placing a coloured narrowband interference filter (B-40 filters, Balzers, Liechtenstein; $15 \mathrm{~nm}$ FWHM bandwidth) and a heat filter in the light path to illuminate the drum. All other light was excluded.

Threshold sensitivity at different wavelengths was tested by monitoring the fish's responsiveness at decreasing light intensities until the point at which the fish no longer tracked the moving stripes. Variable light intensity was achieved through the addition of a transformer and variable power supply to the projector bulb, allowing the light intensity to be reduced. Fish behaviour was observed by using an infra-red camera (Henry's CCTV Co., London, U.K.), with built in infra-red illumination, attached at the top of the convex mirror and providing output to an external television monitor. White light was provided by removal of the interference and heat filters from the light source such that the drum was illuminated with 'white' projector light. This was carried out in order to maintain light-adaptation, and hence the testing of photopic sensitivity.

Light levels at threshold were measured using a spectrally calibrated irradiance meter (International Light Inc., IL1700 Research Radiometer, U.S.A.), fixed beside the drum. Light readings were taken at maximum intensity (to ensure consistency of projector output) and at threshold for every filter and fish.

Individual fish were selected from the holding tank and transferred to the experimental chamber within the optomotor apparatus. Prior to testing, an initial acclimation phase was allowed. This began with $30 \mathrm{~s}$ adaptation under white light from the projector. The motor was then started and the fish's responsiveness to the moving stimulus was tested with both $\mathrm{CW}$ and CCW drum rotation under this full intensity white light. Observed responses consisted of either full tracking of the stripes around the outside of the tank, or head and body turning in the direction of rotation. An interference filter and heat filter was placed in the light path and a light measurement at this maximum light intensity was taken to check consistency of output.

Trials consisted of two phases: a rest phase (drum motor off), lasting $10 \mathrm{~s}$ and a test phase, lasting up to $30 \mathrm{~s}$, when the motor was turned on and the fish's response was monitored. Each fish was tested at maximum light intensity. The drum was started (CW or $\mathrm{CCW}$ rotation randomized) and a positive response was noted if the fish exhibited a clear response to the moving stripes within a period of $30 \mathrm{~s}$ from which latency (i.e. time to response) was recorded. The light intensity of the projector was then decreased and a $10 \mathrm{~s}$ rest phase was followed by drum rotation to test the fish at the lower light intensity. Four light intensities were tested in each block before a period of $30 \mathrm{~s}$ of white light was allowed in order to maintain a constant state of light adaptation. The threshold sensitivity for any given wavelength was taken to be the lowest irradiance at which the fish tracked the moving stripes. This was confirmed through the reversal of the drum and observation of the fish's behaviour. Measurements at threshold were made both in photons $\mathrm{cm}^{-2} \mathrm{~s}^{-1}$. In total, each fish was tested using 10 interference filters, with median transmissions of: 415, 437, 459, 506, 552, 578, 602, 648, 677 and $713 \mathrm{~nm}$, (corresponding to nominal maximum wavelengths of transmission of 406, 432, 454, $501,575,595,645,670$ and $708 \mathrm{~nm})$. Filters were presented in a random order and assessment time for each filter was kept below $3 \mathrm{~min}$ to avoid dark adaptation (which in preliminary trials was not found to occur within $3 \mathrm{~min}$ ). Statistical comparison of optomotor thresholds between morphs was carried out using repeated measures, multivariate General Linear Models (GLM) using unrelativized $\log _{10}$-transformed threshold data.

\section{MODELLING SPECTRAL SENSITIVITY}

The scotopic (low light) spectral sensitivity of the peacock blenny was predicted using an additive model. The absorptance spectra of the rod visual pigments found during MSP were constructed for different mixtures of rhodopsin and porphyropsin analogues (Parry \& Bowmaker, 2000) using the visual pigment templates of Govardovskii et al. (2000). Relative absorptances of the two pigments were calculated taking into account the relative 
rhodopsin and porphyropsin extinction coefficients (Knowles \& Dartnall, 1977), cell outer segment lengths and calculated chromophore ratios. They were adjusted for the transmission of the ocular lens, summed in a variable ratio and plotted on a logarithmic scale.

The model assumed that the rod is a visual pigment based upon a single opsin which, when combined with an $A_{1}$ chromophore, has a $\lambda_{\max }$ of $499 \mathrm{~nm}$ and, when combined with $\mathrm{A}_{2}$, has a $\lambda_{\max }$ of $516 \mathrm{~nm}$. An outer segment length of $8 \mu \mathrm{m}$ and maximum corrected absorbance of $0.016 \mu \mathrm{m}^{-1}$ was determined from the MSP measurements. The relative photon catches for the two pigments were adjusted for the lower $(70 \%)$ relative extinction coefficient of porphyropsin and accounted for lens cut-off.

\section{RESULTS}

\section{MSP}

Frequencies of OTT $\lambda_{\max }$ values for all fish are presented in Fig. 2. A rod visual pigment was measured (in nine out of 12 fish) with mean OTT $\lambda_{\max }$ of $508 \mathrm{~nm}$, (range of means, 503-515 nm), suggestive of a single opsin forming visual pigments with mixtures of $\mathrm{A}_{1}$ and $\mathrm{A}_{2}$ chromophores. Cone pigments were found with OTT $\lambda_{\max }$ values ranging from 508 to $577 \mathrm{~nm}$. Such a range of values cannot be accounted for by the presence of one cone opsin, even supposing a mixed chromophore component: a $508 \mathrm{~nm} \lambda_{\max }$ rhodopsin has as its porphyropsin analogue a $529 \mathrm{~nm}$ porphyropsin (Parry \& Bowmaker, 2000), a

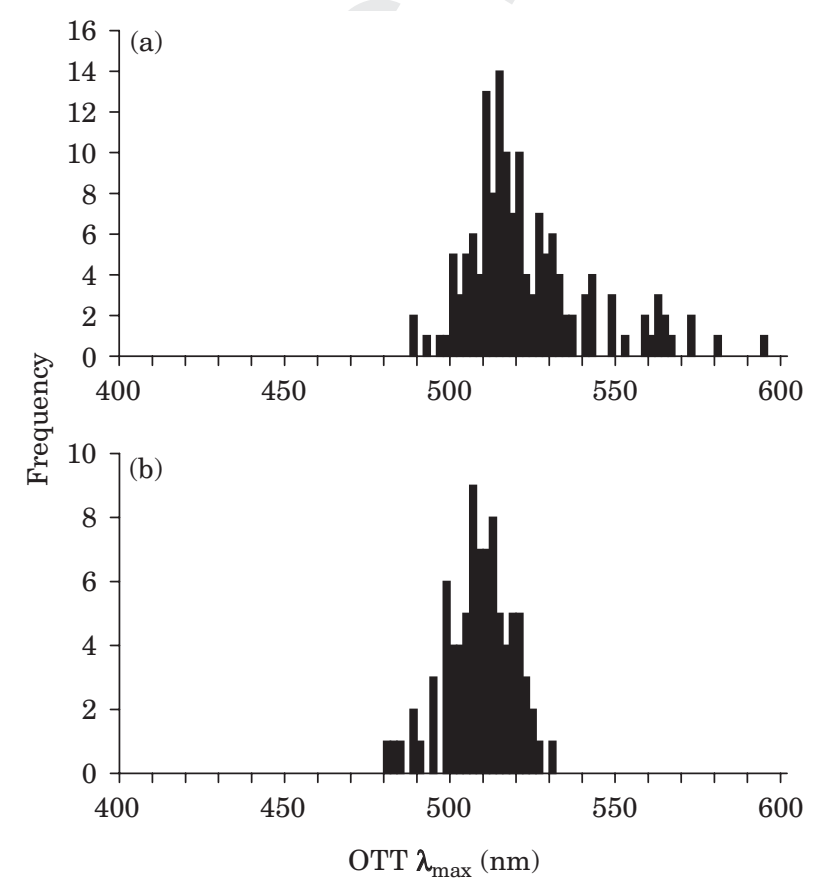

FIG. 2. Frequency histogram showing total number of MSP measurements (OTT $\lambda_{\max }$ in 2 nm intervals) for all fish used in this study (four males, four females and four sneakers). (a) Cone visual pigments and (b) rods. The broad spread of cone pigments indicates the presence of more than one opsin, the variation being attributable to variation in chromophore incorporation. 
value well short of the maximum long-wave $\lambda_{\max }$ found $(577 \mathrm{~nm})$. In the midwavelength sensitive (MWS) region, 11 out of 12 fish had cone pigments with mean OTT $\lambda_{\max }$ in the range $508-535 \mathrm{~nm}$, which may be attributable to visual pigments formed from a single cone opsin with variable chromophores. In seven fish (two males, three females and two sneakers), more long-wavelength sensitive (LWS) cones was found with mean OTT $\lambda_{\max }$ in the range $536-577 \mathrm{~nm}$ (mean for this range, $555 \mathrm{~nm}$ ). Given knowledge of the relationship between visual pigment $\lambda_{\max }$ and chromophore ratio (Parry \& Bowmaker, 2000), the MWS and LWS cells cannot be attributable to the same opsin, and hence the peacock blenny expresses at least two different cone opsins which form visual pigments having $\lambda_{\max }$ values in the range $508-577 \mathrm{~nm}$.

Few intact double cones were found, however those that were found $(n=5)$ were always sensitive at long-wavelengths $(>540 \mathrm{~nm})$, at least in the outer segments that were measurable. In only two cases did MSP data from both members pass selection criteria, and these were found to have OTT $\lambda_{\max }$ values of 541 and 572 , and 558 and $564 \mathrm{~nm}$. No short-wavelength sensitive (SWS) cones were found.

Example absorbance spectra from MSP data are shown in Fig. 3. The rod and cone OTT $\lambda_{\max }$ values found for females, sneakers and males are presented in Table I.

\section{VISUAL PIGMENT EXTRACTION: DETERMINATION OF CHROMOPHORE RATIOS}

Partial bleaching experiments revealed the presence of two extractible visual pigments in the blenny rod: one pigment fitting a porphyropsin $\left(\mathrm{A}_{2}\right)$ template with $\lambda_{\max }$ at $515 \cdot 8 \mathrm{~nm}$ and another fitting a rhodopsin $\left(\mathrm{A}_{1}\right)$ template with $\lambda_{\max }$ at 498.8 (Fig. 4). The identity of the chromophore was confirmed by a shift of the photoproduct $\lambda_{\max }$ (seen as absorption minima in Fig. 4). Porphyropsins generally have a photoproduct peak of c. $382 \mathrm{~nm}$, compared to the rhodopsin photoproduct peak of $374 \mathrm{~nm}$ (Knowles \& Dartnall, 1977). Using the Parry \& Bowmaker (2000) equation for the relationship between rhodopsin and porphyropsin pigments with the same opsin, a rhodopsin pigment with a $498 \cdot 8 \mathrm{~nm} \lambda_{\max }$ would have a porphyropsin pair with $\lambda_{\max }$ at $516.4 \mathrm{~nm}$.

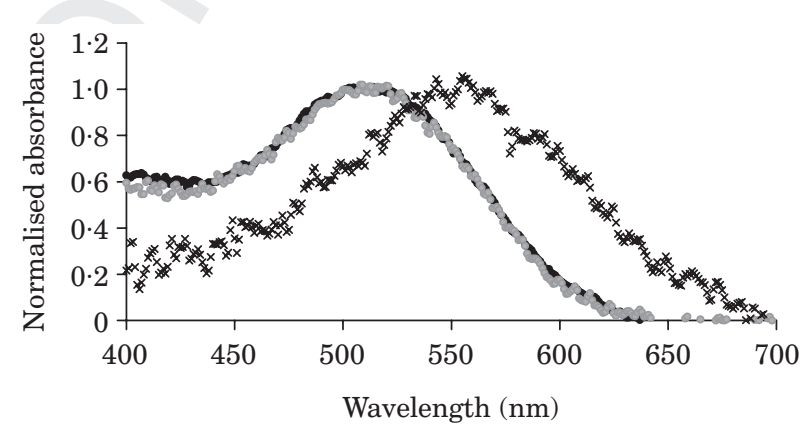

FIG. 3. Example absorbance curves from MSP data: the normalized absorbance of the retinal photoreceptors of female fish, merging all records. Data shown are for rods $(\bullet)$, and for the mean of two possible cone classes in each of the wavebands: 508-535 nm (•) and 535-566 nm (x), assuming two opsins are expressed at approximately these positions. In female fish, no cones were found between 530 and $540 \mathrm{~nm}$. 
TABle I. 'Over-the-top' $\lambda_{\max }$ values of normalized absorbance for rods and cones of females, sneakers and nesting males of $S$. pavo. The broad range of cone pigments found indicates the presence of more than one opsin

\begin{tabular}{lccc}
\hline & Females & Sneakers & Males \\
\hline Rods & & & \\
Mean (nm) & 509 & 514 & 505 \\
Range (nm) & $506-511$ & $511-515$ & $503-506$ \\
$n$ (fish) & 2 & 3 & 4 \\
Cones & & & $510-543$ \\
Range (nm) & $508-566$ & $411-577$ & 4 \\
$n$ (fish) & 4 & 4 & \\
\hline
\end{tabular}

This information was used to ascertain chromophore ratios in the rods of individual peacock blennies. The OTT $\lambda_{\max }$ values of averaged rod absorbance spectra were determined from MSP measurements of each fish. A computer
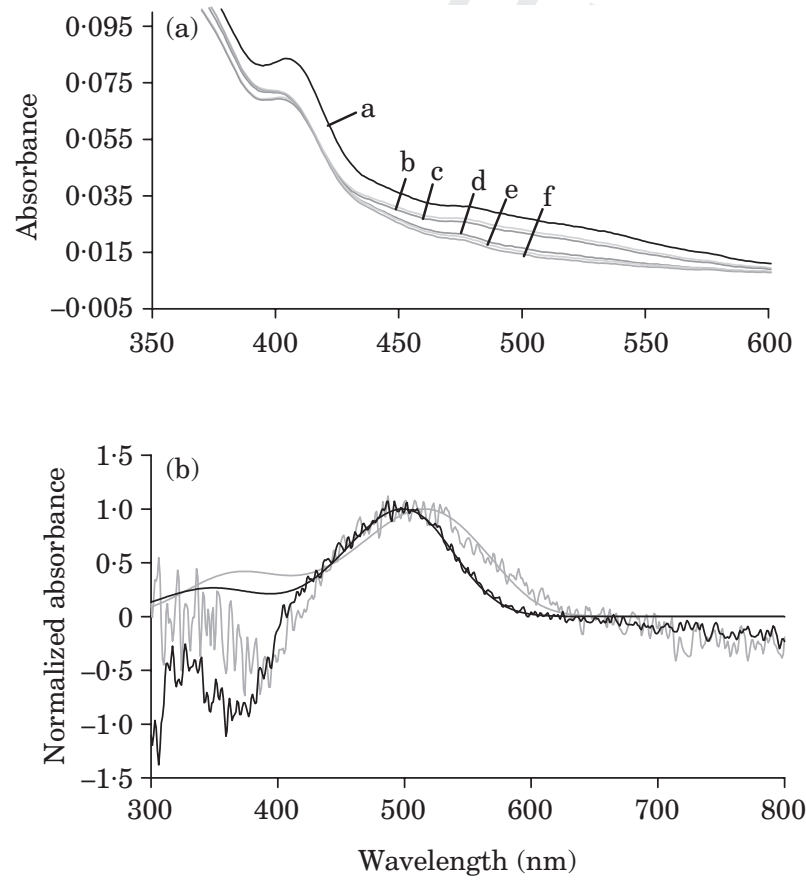

FIG. 4. (a) Absorptance spectra measurements in the partial bleaching experiment (averaged data from four animals). $\mathrm{a}$, indicates the absorptance spectrum of the raw extract; and $\mathrm{b}-\mathrm{f}$, the spectra obtained after each of the successive bleaches: b, $15 \mathrm{~min}$ at $660 \mathrm{~nm}$;, $15 \mathrm{~min}$ at $648 \mathrm{~nm}$; d, $10 \mathrm{~min}$ at $559 \mathrm{~nm}$; e, $10 \mathrm{~min}$ at $506 \mathrm{~nm}$; f, $10 \mathrm{~min}$ white light. (b) Normalized difference spectra resulting from partial bleaching for $S$. pavo rod extracts, with best-fit templates. _, the spectrum and fitted-template for a porphyropsin pigment with $\lambda_{\max }$ of $515.8 \mathrm{~nm}$; - , the spectrum and fitted-template for a rhodopsin pigment with $\lambda_{\max }$ of $498.7 \mathrm{~nm}$. Difference spectra were constructed from $656 \mathrm{~nm}$ to $645 \mathrm{~nm}$ (bleaching of the $\mathrm{A}_{2}$ pigment) and 560 to $501 \mathrm{~nm}$ (bleaching of the $\mathrm{A}_{1}$ pigment), respectively and indicate the presence of a pigment pair based upon the same opsin. 
model was constructed using Microsoft Excel 2000. This simulated mixtures of the known (from extract spectrophotometry) rod visual pigments (using the visual pigment template of Govardovskii et al., 2000 and taking rhodopsin and porphyropsins $\lambda_{\max }$ values of 498.8 and $516.4 \mathrm{~nm}$, respectively), and iteratively calculated the OTT $\lambda_{\max }$ values of the mixtures. The model took into account the lower extinction coefficient of porphyropsin and used a value of $70 \%$ of that of rhodopsin pigments (Knowles \& Dartnall, 1977). By matching the simulated OTT $\lambda_{\max }$ with the values measured from the rods of each fish by MSP, an estimation of the rhodopsin: porphyropsin $\left(\mathrm{A}_{1}: \mathrm{A}_{2}\right)$ ratio in these photoreceptors was derived. This indicated that individual fish ranged from 4 to $60 \%$ rhodopsin (mean value for the nine fish for which rod cells were found, $30 \%$ rhodopsin). Average percentages of rhodopsin for males, females and sneakers were: $47 \%($ range $=37 \cdot 8-57 \cdot 4 ; n=4), 27 \%($ range $=16 \cdot 7-37 \cdot 8 ; n=2)$ and $12 \%$ (range $=3 \cdot 9-16 \cdot 7 ; n=3$ ) respectively.

\section{RETINAL CAROTENOIDS}

It was observed during analysis of the MSP scans that several outer segments contained a photo-stable pigment as well as the visual pigment. This was observed in measurements collected after bleaching and created sufficient distortions in the pre-bleach absorption spectra that the $\lambda_{\max }$ of the visual pigment could only be determined using difference spectra. Average files were made of this photo-stable pigment (Fig. 5), indicating a three-peaked absorption spectrum, typical of carotenoids, with peaks at 421, 452 and $481 \mathrm{~nm}$. This putative carotenoid was found in 17 out of 177 MWS cells $(10 \cdot 1 \%)$ and in two out of 37 LWS cells $(5 \cdot 4 \%)$. It was found in the cells of three males, two females and one sneaker.

The presence of photostable pigments in the eye was also explored by making vertical sections of the eye of one peacock blenny. Spectrophotometric measurements of these sections revealed a $25 \mu \mathrm{m}$ layer of yellow pigment. This pigment

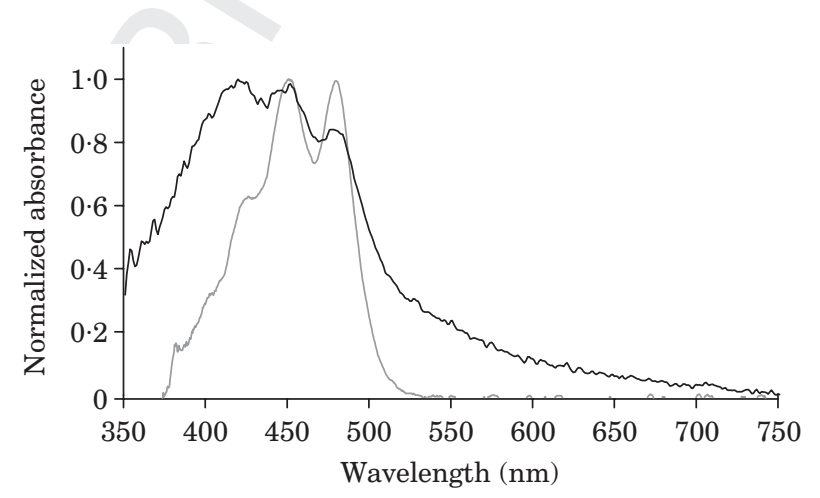

FIG. 5. Absorbance spectrum for the photo-stable product found in the S. Pavo retina. - , spectrum from cone outer segments with peaks at 421,451 and $481 \mathrm{~nm}$ determined using MSP; - , absorbance spectrum for carotenoid pigment found scleral to the retinal pigment epithelium and measured in retinal sections. Peak absorbance values fall at 423, 452 and $481 \mathrm{~nm}$. The absorbance of the MSP scan is elevated at short-wavelengths by the presence of bleached visual pigment in the outer segment. 
resembled uncontaminated carotenoids with peaks at c. 423, 452 and $481 \mathrm{~nm}$ (Fig. 5) and was evenly distributed around the eye, scleral to the retinal pigment epithelium. A composite photograph of a section through the peacock blenny eye, taken anterior to the pupil aperture is shown in Fig. 6.

\section{TRANSMISSION OF THE LENS}

The mean lens diameter was $1.30 \mathrm{~mm}$ for males (range $=1.12-1.47 \mathrm{~mm}$ ), $1.21 \mathrm{~mm}$ for females (range $=1.20-1.22 \mathrm{~mm}$ ) and $1.12 \mathrm{~mm}$ for sneakers (range $=1 \cdot 07-1 \cdot 17 \mathrm{~mm})$.

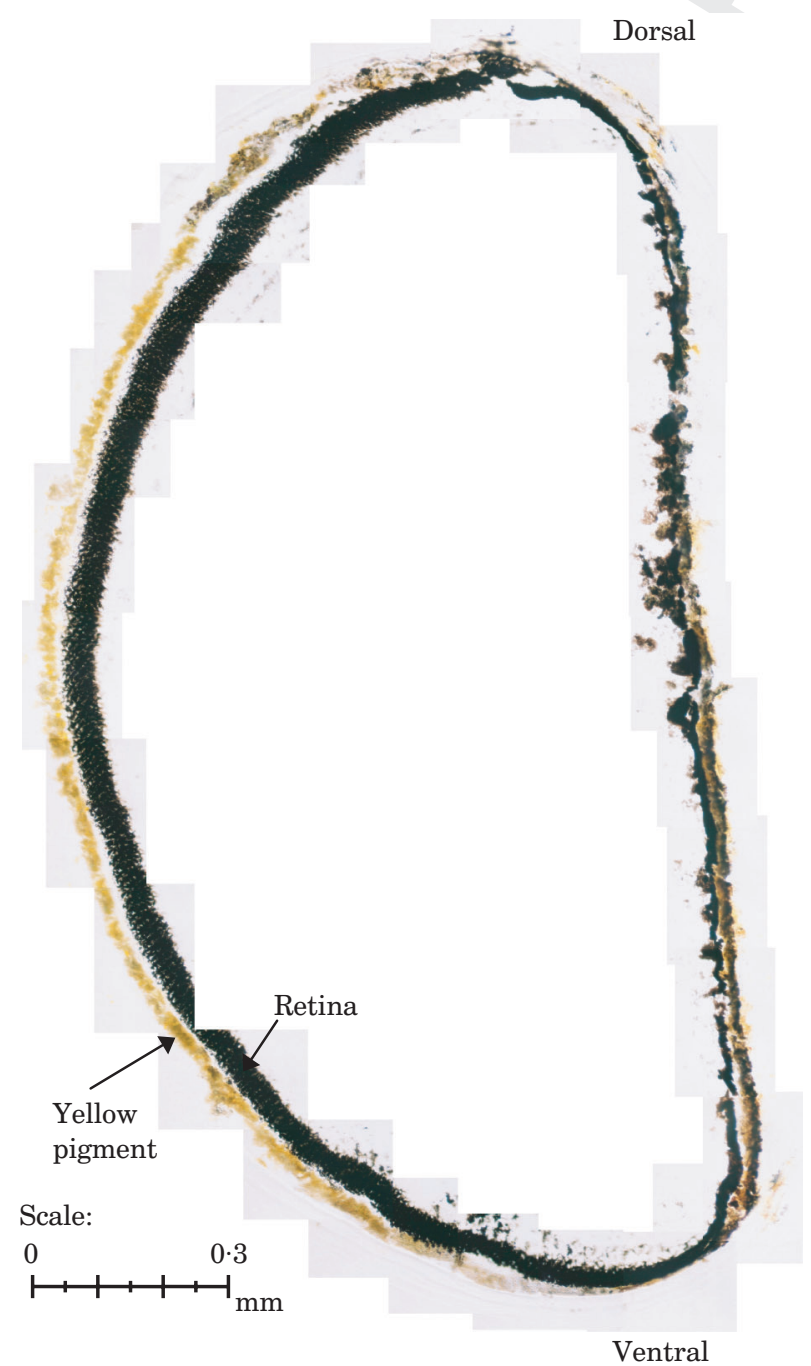

FIG. 6. Composite photograph showing the positioning of the yellow pigment around the eye of S. pavo. This section $(25 \mu \mathrm{m}$ thick) was made anterior to the pupil aperture and hence a complete section, without pupil aperture, is observed. 
All lenses transmitted evenly over the range of $c .440-800 \mathrm{~nm}$ but had a shortwavelength cut-off (defined as wavelength of $50 \%$ transmission) at $420 \mathrm{~nm}$ (range $=415-425 \mathrm{~nm}$; Fig. 7). The mean cut-off (and range) for females, sneakers and males (defined as wavelength of $50 \%$ transmission) was $422 \mathrm{~nm}(418-425$; $n=4), 420 \mathrm{~nm}(417-423 ; n=3)$ and $420 \mathrm{~nm}(415-422 ; n=3)$, respectively.

\section{ACTION SPECTRUM FOR THE OPTOMOTOR RESPONSE}

The mean optomotor threshold values measured for males, females and sneakers against the median wavelength of 10 narrow band interference filters, plotted as $\log _{10}$ relative sensitivity is shown in Fig. 8 . The reciprocal of the threshold (sensitivity) was expressed relative to the maximal value of each fish (Schaerer \& Neumeyer, 1996) and means \pm S.E. of these means for each morph were then calculated.

A significant difference was found between the optomotor response thresholds of the different morphs (filter $\times$ morph interaction; Wilk's lambda $=0 \cdot 129$, $\left.F_{18,24}, P=0.024\right)$, i.e. the 'shape' of the morph's optomotor action spectra were significantly different) suggesting a significant difference between the three groups. This difference in spectral shape was further explored using withinsubjects contrast analysis that compared the morph $\times$ filter interaction for each filter condition with the overall mean threshold value for each morph. Although overall the morphs' spectral sensitivities were found to differ significantly from one another, contrast analysis between the morphs for the individual filters were not significant $(P>0 \cdot 100$, i.e. the morph $\times$ filter interaction for individual filters was not significantly different from the overall mean), with the exception of filter $674 \mathrm{~nm}$, where there was a significant difference between the threshold sensitivity for sneakers and the mean for all morphs $\left(F_{2,20}, P=0.003\right)$. In conclusion, the three morphs had action spectra that were, overall, significantly different from one another in spectral shape. By inspection of the data in can be seen that sneakers have a broader spectral sensitivity than males or females, the

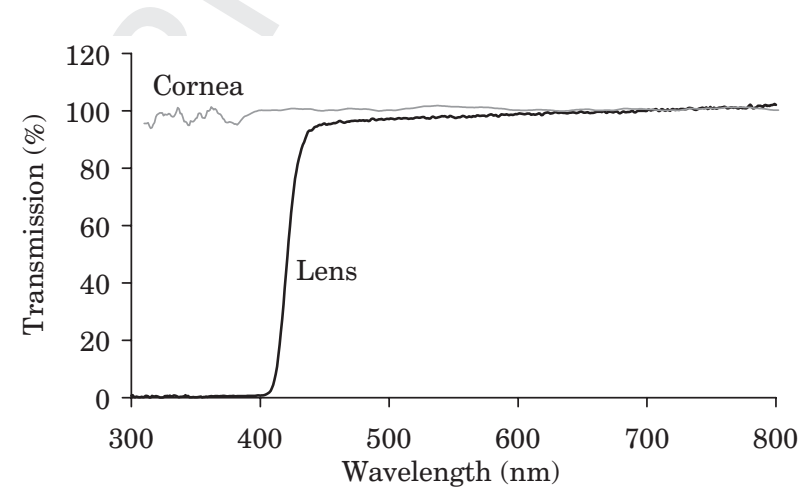

FIG. 7. Transmission spectra of the lens (-) and cornea (-) from 300 to $800 \mathrm{~nm}$. Mean transmission of the lens is shown for 10 animals. Cut-off (defined as wavelength of $50 \%$ transmission) occurred at $420 \mathrm{~nm}$. Corneal measurements (smoothed with a 21 point running average) are made from one animal and shown no significant absorbance across the $300-800 \mathrm{~nm}$ range. Noise in the data set between 300 and $400 \mathrm{~nm}$ is attributable to the low levels of UV in the light source between these wavelengths. 


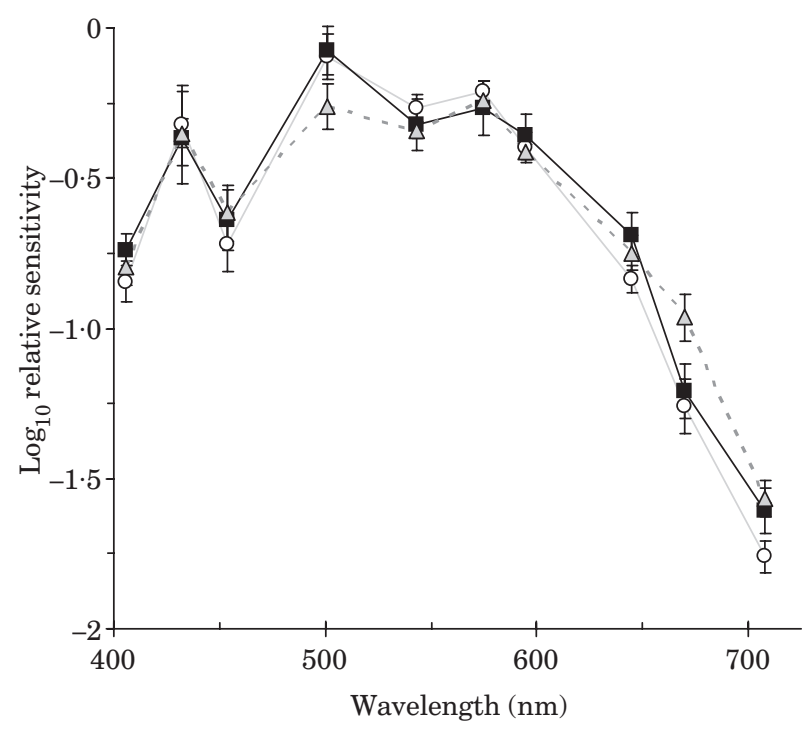

FIG. 8. Optomotor action spectra for eight males (O), eight females ( $\mathbf{a})$ and eight sneakers $(\Delta)$. For each morph the mean \pm S.E. response is plotted as the $\log _{10}$ of relative sensitivity, achieved by scaling data for every fish to its own maximum.

wavelength of their maximum sensitivity is displaced to long-wavelengths $>70 \mathrm{~nm}$ compared with males or females, and is elevated at long-wavelengths.

Since sneakers develop into males, the possibility that variations in the optomotor action spectra were due to differences in size between individuals was explored. This was carried out by including size (standard length, $L_{\mathrm{S}}$, of animals) as a covariate in GLM. No filter $\times$ size interaction was found (Wilk's lambda $\left.=0.549, F_{9,11}, P=0 \cdot 49\right)$ and adding size to the model did not abolish the filter $\times$ morph interaction (Wilk's lambda $=0 \cdot 134, F_{18,22}, P=0 \cdot 048$ ). Therefore the statistically different spectral sensitivity of the sneaker morphs cannot be attributable to their size.

\section{MODELLING SPECTRAL SENSITIVITY}

The predicted scotopic spectral sensitivity of two fish with relative chromophore ratios of $60 \%$ rhodopsin and $4 \%$ rhodopsin, the range of difference found in the individual fish used in this study, is illustrated in Fig. 9. This shows that the greater incorporation of porphyropsin chromophore causes a shift in sensitivity to longer wavelengths and a broadening of the spectral range. It may be hypothesized that an animal with high chromophore variation in its rods, will also exhibit differences in chromophore content in its cones, and this show similar (and probably greater) variation in its photopic sensitivity.

The predicted scotopic spectral sensitivity curve is a poor fit to the optomotor action spectrum, reinforcing the conclusion that this is a cone-driven response. It is not possible to accurately model photopic (cone mediated) spectral sensitivity without accurate information on the exact placing of the cone $\lambda_{\max }$ values, and relative cone ratios. As rod chromophore ratios differed between the 


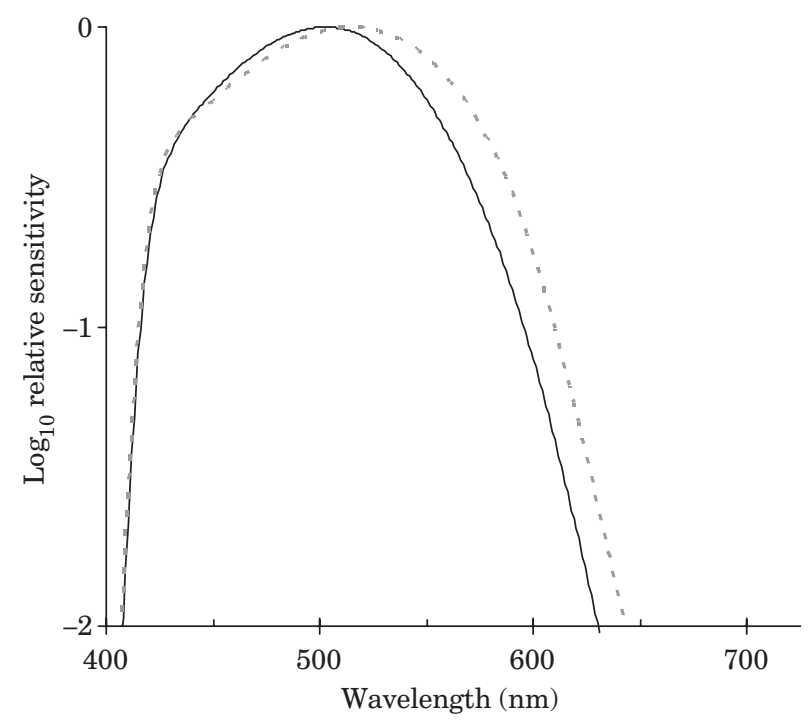

FIG. 9. Results of modelling the scotopic spectral sensitivity of the peacock blenny: the predicted spectral sensitivity of two measured fish, a sneaker with $4 \%$ rhodopsin (-=) and a male with $60 \%$ rhodopsin (-) in the rod visual pigments. Fish with lower rhodopsin (higher porphyropsin) retinal content have a broader spectral range with increased long-wavelength sensitivity.

morphs (males having 47.2\% $\mathrm{A}_{1}$, females having $27 \cdot 3 \% \mathrm{~A}_{1}$ and sneakers having $12.4 \% \mathrm{~A}_{1}$ ), however, it is possible that cone chromophore ratios vary similarly. Such variation would account for the differences in breadth of the sensitivity spectra found using the photopic optomotor response.

\section{DISCUSSION}

Information on the visual capabilities of intertidal fishes is generally very scarce (Loew \& Lythgoe, 1978; Lythgoe \& Partridge, 1989). The aim of this investigation was to explore the spectral sensitivity of an intertidal fish, the peacock blenny, from a physiological and behavioural perspective and to test the hypothesis that visual variation might occur between morphs of the same species. It can be hypothesized that within-species variation in vision may occur when individuals inhabit different microhabitats within a diverse light environment, or have different visual requirements in order to perform behavioural tasks. During the breeding season, S. pavo males guard eggs and seldom leave their nests. In this context, it would be adaptive for them to try to discriminate females from small sneaker males that steal fertilizations of the guarded eggs. Females spend most of their time outside the breeding areas and only approach nests to spawn or to assess males, which they see against background of the nest. Sneakers stay in the vicinity of successful nest sites and try to fertilize eggs when ripe females approach (Gonçalves et al., 2003). Thus, during the breeding season, males, females and sneakers occupy different microhabitats, which differ in light conditions (M. Cummings, D. Gonçalves, E. White \& R. Oliveira, 
unpubl. data), and there is variation in the visual tasks that each morph needs to accomplish.

MSP revealed the presence of a rod pigment with an average (OTT) $\lambda_{\max }$ of $510 \mathrm{~nm}$, and cone pigments in the range $508 \mathrm{~nm}-577 \mathrm{~nm}$. There was high individual variation in rod and cone $\lambda_{\max }$ between and within individuals. The high intraspecific variation in photoreceptor $\lambda_{\max }$, such as the one observed, is commonly caused by variations in the chromophoric group (Bridges, 1972). Indeed, partial bleaching experiments revealed two rod visual pigments, one a porphyropsin with $\lambda_{\max }$ at $515.8 \mathrm{~nm}$, and a rhodopsin with $\lambda_{\max }$ of $498.8 \mathrm{~nm}$. Given knowledge of the relationship between the $\lambda_{\max }$ of rhodopsin and porphyropsin pigments (Dartnall \& Lythgoe, 1965; Whitmore \& Bowmaker, 1989, Parry \& Bowmaker, 2000) this indicates a rhodopsin and porphyropsin pigment pair based upon the same rod opsin. As the rod pigments of individual fish varied in the $A_{1}: A_{2}$ ratio, the cone pigments are also likely to vary similarly. Thus, the most parsimonious interpretation of the rod and cone absorbance spectra derived by microspectrophotometry is that they can be explained as mixtures of at least three pairs of visual pigments, each pair based on different opsins and being confined to three photoreceptor types (one rod and two cones). Variation in rod and cone $\lambda_{\max }$ seen in MSP measurements can thus be interpreted as variation in the chromophore $A_{1}: A_{2}$ ratio in the visual pigments of different fish. Since the range of cone OTT $\lambda_{\max }$ values spreads a $70 \mathrm{~nm}$ range, this indicates that at least two cone opsins are present, in addition to variation in chromophore content.

The mean rod chromophore utilization for all fish was $30 \% \mathrm{~A}_{1}$ and $70 \% \mathrm{~A}_{2}$. This high $\mathrm{A}_{2}$ content is at variance with previous findings that porphyropsins are generally associated with freshwater fish visual systems and rhodopsins with marine environments (Beatty, 1984). The peacock blenny is an exception to this general 'rule' in having a mixed chromophoric system. Mixed systems have, however, been found in other marine fishes such as surfperches (Embiotocidae; Cummings \& Partridge, 2001), labrids and scarids (Lythgoe, 1972; Munz \& McFarland, 1977), and deep-sea fish (Stomidae) in which individual rods may contain rhodopsin or porphyropsin analogues based on the same opsin (Bowmaker et al., 1988; Partridge et al., 1989). Mixed chromophoric groups have been hypothesized to be advantageous in optically variable habitats, in which adjustments in the $A_{1}: A_{2}$ ratio could provide plasticity in an animal's spectral sensitivity in response to changes in environmental conditions (Loew \& Dartnall, 1976; Levine \& MacNichol, 1979; Cummings \& Partridge, 2001). Plasticity of this type could also be advantageous for animals that need to perform different visual tasks at different times, e.g. during and outside the breeding season. In some species, a seasonal variation in the retinal $\mathrm{A}_{1}: \mathrm{A}_{2}$ ratio has been demonstrated, this being correlated with changes in the environmental light (Dartnall et al., 1961; Levine \& MacNichol, 1979; Muntz \& Mouat, 1984). Variation in spectral sensitivity has been reported for three-spined stickleback Gasterosteus aculeatus L., that occupy different photic regimes (McDonald \& Hawryshyn, 1995; Boughman, 2001). In this species female sensitivity to red light has been found to correlate with the degree of male nuptial colouration, which in turn is dependent on the light environment (Boughman, 2001). Threespined sticklebacks have a dual rhodopsin-porphyropsin based visual system 
(Ali \& Wagner, 1975), however, the precise mechanism underlying variation in female perception has yet to be elucidated.

For $S$. pavo a mixed chromophoric group in the retina could be particularly advantageous as photic conditions in temperate coastal environments like the Ria Formosa are highly variable and the visual tasks animals need to perform vary both seasonally (e.g. within and outside the breeding season) and ontogenetically (e.g. sneakers develop into bourgeois males that defend nests; D. Gonçalves, T. Fagundes \& R.F. Oliveira, unpubl. data). The similarity of the $S$. pavo retina with freshwater species (i.e. in having porphyropsin visual pigments) could also reflect its phylogeny. Salaria pavo is thought to be the closest relative to the only species of North Atlantic and Mediterranean blenny that inhabits freshwater, Salaria fluviatilis (Asso) (Zander, 1973). Some authors have argued that S. fluviatilis was a polytopic derivative of $S$. pavo (Kosswig, 1967) while others have suggested that both species derived c. 5-7 million years ago from an eurythermal and euryhaline common ancestor which tolerated the desalinization of the Mediterranean in the upper Pliocene (Zander, 1973; Perdices et al., 2000). The photic conditions of the Mediterranean have probably changed markedly during its successive cycles of salinization and desalinization, and S. pavo, or its euryhaline ancestor, may have developed a mixed chromophoric retina during this process, probably highly adaptive under these variable conditions. Future comparative spectral sensitivity and molecular biology studies among the Salaria spp. could provide valuable data to disentangle the evolutionary history of the genus.

Threshold sensitivities, determined using the optomotor response, were found to vary significantly among $S$. pavo morphs. Whilst all action spectra followed a broadly similar shape, sneakers had a broader sensitivity that was particularly elevated at long-wavelengths and had its wavelength of maximum sensitivity displaced to longer wavelengths than either females or males. The possibility that this variation might be a consequence of size, rather than morph per se was explored, but the responses of larger sneakers and females was not found to approach the responses of smaller males, and no size effect was found overall.

It is likely that variation in the optomotor response data obtained from morphs could be due to differences in chromophore incorporation in retinal cone visual pigments. Chromophore analysis for rod visual pigment extracts demonstrated differences in the ratio of rhodopsin:porphyropsin in the rod photoreceptors of different morphs and modelling the effect of this variation on scotopic spectral sensitivity demonstrated the possible magnitude of spectral sensitivity differences. Samples sizes were too small to allow statistical analysis, but there was a distinct trend for high $\mathrm{A}_{1}$ chromophore levels in males $(47 \%$, $n=4)$, medium levels in females $(27 \%, n=2)$, and very low in sneakers $(12 \%$, $n=3$ ). If similar levels of variation in chromophore ration also occur in the cone visual pigments this may account for the differences detected in the photopic optomotor responses of individual and morphs. Putatively, such variation in spectral sensitivity may be a manifestation of a physiological adaptation to morph-specific visual tasks.

It is well known that individual fish can change their visual pigment chromophore utilisation over time. Species such as the rudd (Bridges, 1972; Whitmore \& Bowmaker, 1989), and some trout Salmo sp. (Allen et al., 1973), show seasonal 
changes in chromophore content within the retina. Thus it is possible that the chromophore content of the peacock blenny retina might also be variable over time, allowing adaptation to seasonal changes in the environment or in visual tasks performed.

In all behavioural measures of spectral sensitivity, the resulting curve depends on the task that the subject is required to do and the visual mechanisms behind it (Jacobs, 1993). In previous experiments on other teleosts, the optomotor response, which is based upon the perception of movement, has been found to be driven predominantly by the long-wavelength photoreceptors (Schaerer \& Neumeyer, 1996). In such cases, the resulting action spectrum has provided in a single maximum and a close fit to the long-wave-sensitive photoreceptor spectral sensitivity. In the peacock blenny, however, no single maximum was found, and there were indeed distinct minima, between the short and medium, and medium and long-wave regions of the spectrum. This is unlike the optomotor action spectra documented for the goldfish Carassius auratus auratus (L.) (Schaerer \& Neumeyer, 1996), zebrafish Danio rerio (Hamilton) (Krauss \& Neumeyer, 2003) or guppy Poecilia reticulata pates (Anstis et al., 1998; Endler et al., 2001), which have one maxima. This might indicate that more than one receptor contributes to motion-detection in the peacock blenny, or it may be that an alternative mechanism, such as chromatic filtering, may significantly alter the absorption spectra of retinal cones. A photo-stable carotenoid pigment similar to lutein or zeaxanthin was present in some of the cone outer segments scans from MSP (17 out of 177 MWS cells and two of 37 LWS). Carotenoids have never before been recorded in the outer segments of fish photoreceptors, although they have been found in the lenses and corneas of teleosts and sharks (Muntz, 1973; Zigman \& Gilbert, 1978; Kondrashev et al., 1986; McFall-Ngai et al., 1986; Thorpe et al., 1993), as well as in gecko lenses (Roll, 2000) and in the retinal oil droplets of birds (Hart, 2001) and reptiles (Liebman \& Granda, 1975). They are present in the human macula lutea (Snodderly et al., 1983; Sommerberg et al., 1999) and rod and cone outer segments of the human perifoveal and peripheral retina (Bone et al., 1988; Bone et al., 1997; Sommerberg et al., 1999; Rapp et al., 2000). Although the carotenoids found in association with the $S$. pavo cone visual pigment during MSP appeared to be within the cone outer segments, it is possible that they could have contaminated the cells from elsewhere in the retina during the preparation process. Specifically, a $25 \mu \mathrm{m}$ thick layer of carotenoid was found distributed throughout the eye, scleral to the retinal pigment epithelium. This carotenoid exhibited absorbance peaks similar to those found in the MSP scans (421, 452, $481 \mathrm{~nm}$ compared with 423, 452, $481 \mathrm{~nm}$ from MSP). As far as is known, carotenoids have only been reported in such quantities in the retinae of two other fish species. These are the south American cichlid Crenicichla lenticulata Heckel, which has been found to have large quantities of unidentified photo-stable yellow pigment in the retina (Muntz, 1973), possibly to protect against photo-oxidative damage, and the deep-sea dragon fish Malacosteus niger Ayres, which possesses a carotenoid(astaxanthin) based red tapetum (Somiya, 1982; Bowmaker et al., 1988) for enhanced sensitivity of its own far-red bioluminescence (Douglas et al., 1999).

Given that the peacock blenny is a highly diurnal species (Plaut \& Afik, 2001), it seems likely that the carotenoid layer performs a protective role. In 
wrasse (Labridae) and parrotfishes (Scaridae), carotenoid pigments absorbing maximally at c. $450 \mathrm{~nm}$ are found in the cornea, predominantly concentrated in the dorsal region (Moreland \& Lythgoe, 1968). These pigments selectively filter the blue component of downwelling light, like an eyeshade, and are thought to decrease short-wavelength damage and chromatic aberration whilst increasing acuity and contrast perception (Walls \& Judd, 1933; Heinermann, 1984). Similarly, in the human macula, carotenoids are thought to prevent or limit light and oxygen damage to the retinal cells (Kirschfield, 1982; Schalch, 1992). It is thus possible that in $S$. pavo carotenoids may be involved in protecting the retina from short-wavelength damage by scavenging free radicals and preventing photo-oxidative damage.

Fishes living in shallow waters commonly have a short-wavelength filter in the lens or cornea (Siebeck \& Marshall, 2000; Cummings \& Partridge, 2001). Accordingly, while the cornea of the peacock blenny was found to be transparent, the lens was found to be a UV cut-off filter. Apart from shielding the retina from UV radiation, this cut-off may be particularly useful in the waters of the Ria Formosa, where large amounts of small organic and inorganic particles in suspension scatter light and may produce an obscuring veiling light dominated by short-wavelengths, as suggested for temperate littoral areas (Lythgoe, 1988; Partridge, 1990).

In the MSP investigation, no SWS cones were located although the sample size of accepted cone scans (145) had a high power $(80 \%)$ to detect a cone class as rare as $1.4 \%$ of the total cone population (Cohen, 1988) and there was no indication of SWS cones in the large number of unaccepted scans. To date, published information on other blenniid species is limited only to the shanny Lipophrys (Blennius) pholis (L.) (Loew \& Lythgoe, 1978; Lythgoe \& Partridge, 1989), which was found to have a SWS cone with $\lambda_{\max } 454 \mathrm{~nm}$. For $S$. pavo, the possibility remains that a whole cone class might have been missed at the MSP sampling stage, since this technique can miss classes of receptors if their occurrence is low or if they are not uniformly distributed in the retina (Bowmaker et al., 1978). It should be noted, however, that some blue-water fishes, such as wrasse (Labridae; Levine \& MacNichol, 1979; Losey et al., 2003) also lack SWS cones. This is thought to be an adaptation to the blue space light, which is rich in short-wavelength scatter that reduces contrast and degrades the spatial characteristics of visualized objects, particularly when these are seen at a distance. Although the waters at the Ria Formosa are blue-green in colour (M. Cummings, D. Gonçalves, E. White \& R. Oliveira, unpubl. data), most of the recent evolutionary history of $S$. pavo took place in the bluish waters of the mediterranean. Support for the presence of two cones (MWS and LWS), and the absence of SWS cones in S. pavo also comes from studies of the retinal cone mosaics of various Blennius species. Blennies appear to fall into two categories: those with double cones, and central and accessory single cones, and those with doubles and central singles, but lacking accessory singles (Ali \& Anctil, 1976). Interestingly, $S$. pavo is one species lacking accessory single cones (Zaunreiter et al., 1985), as is S. fluviatilis (Ali \& Anctil, 1976; listed as Blennius vulgaris).

This study provides the first multi-disciplinary investigation of the visual system of an intertidal fish. High variability in chromophore ratios and $\lambda_{\max }$ indicates a visual system that is adaptable and suited to the highly variable 
intertidal environment. Furthermore, there is evidence to suggest that the three morphs (female, sneaker and bourgeois male) of the peacock blenny may have different spectral sensitivities that may be attributable to different chromophore ratios in their retinal photopigments. This may reflect the different visual tasks and different microhabitats with which the morphs are associated.

We are grateful to the direction of the Ria Formosa Nature Park for providing essential logistical support. The authors would like to thank N. Hart for providing the MSP macros, R. Douglas and J. Marshall for their thoughts on carotenoids in the eye, and I. Cuthill, S. Church and M. Cummings for useful discussion. EMW was funded by a University of Bristol Postgraduate Scholarship and DMG by a PRAXIS XXI Ph.D. grant (BD/13436/97). The Portuguese Science and Technology Foundation provided financial support (UI\&D331/94).

\section{References}

Abel, E. F. (1993). Coloration phenomena of Mediterranean blennies (Pisces, Blenniidae). Marine Ecology (PSZNI) 14, 291-312.

Ali, M. A. \& Anctil, M. (1976). Retinas of Fishes: An Atlas. Berlin, Heidelberg, New York: Springer-Verlag.

Ali, M. A. \& Wagner, H.-J. (1975). Visual pigments: ecology and phylogeny. In Vision in Fishes. New Approaches to Research (Ali, M. A., ed.), pp. 481-486. New York: Plenum Press.

Allen, D. M., McFarland, W. N., Munz, F. W. \& Poston, H. A. (1973). Changes in the visual pigments of trout. Canadian Journal of Zoology 51, 901-914.

Almada, V. C., Gonçalves, E. J., Oliveira, R. F. \& Santos, A. J. (1995). Courting females: ecological constraints affect sex roles in a natural population of the blenniid fish Salaria pavo. Animal Behaviour 49, 1125-1127.

Anstis, S., Hutahajan, P. \& Cavanagh, P. (1998). Optomotor test for wavelength sensitivity in guppyfish (Poecilia reticulata). Vision Research 38, 45-53.

Beatty, D. D. (1984). Visual pigments and the labile scotopic visual system of fish. Vision Research 24, 1563-1573.

Beaudet, L. \& Hawryshyn, C. W. (1999). Ecological aspects of vertebrate visual ontogeny. In Adaptive Mechanisms in the Ecology of Vision (Archer, S. N., Djamgoz, M. B. A., Loew, E. R., Partridge, J. C. \& Vallerga, S., eds), pp. 413-437, London: Kluwer Academic Publishers.

Beaudet, L., Novales Flamarique, I. \& Hawryshyn, C. W. (1997). Core photoreceptor topography in the retina of sexually mature Pacific Salmonid fishes. Journal of Comparative Neurology 383, 49-59.

Bone, R. A., Landrum, J. T., Fernandez, L. \& Tarsis, S. L. (1988). Analysis of the macular pigment by HPLC: retinal distribution and age study. Investigative Ophthalmology and Visual Science 29, 843-849.

Bone, R. A., Landrum, J. T., Friedes, L. M., Gomez, C. M., Kilburn, M. D., Menendez, E., Vidal, I. \& Wang, W. (1997). Distribution of lutein and zeaxanthin stereoisomers in the human retina. Experimental Eye Research 64, 211-218.

Boughman, J. W. (2001). Divergent sexual selection enhances reproductive isolation in sticklebacks. Nature 411, 944-948.

Bowmaker, J. K. (1990). The visual pigments of fishes. In The Visual System of Fish (Douglas, R. H. \& Djamgoz, B. A., eds), pp. 81-107. London: Chapman \& Hall.

Bowmaker, J. K. (1996). The visual pigments of fish. Progress in Retinal and Eye Research $15,1-31$.

Bowmaker, J. K. \& Kunz, Y. W. (1987). Ultraviolet receptors, tetrachromatic colour vision and retinal mosaics in the brown trout (Salmo trout): age-dependent changes. Vision Research 27, 2102-2108. 
Bowmaker, J. K., Dartnall, H. J. A., Lythgoe, J. N. \& Mollon, J. D. (1978). The visual pigments of rods and cones in the rhesus monkey, Macaca mulatta. Journal of Physiology 274, 329-348.

Bowmaker, J. K., Dartnall, H. J. A. \& Herring, P. J. (1988). Longwave-sensitive visual pigments in some deep-sea fishes: Segregation of "paired" rhodopsins and porphyropsins. Journal of Comparative Physiology A 163, 685-698.

Bridges, C. D. B. (1972). The rhodopsin-porphyropsin visual system. In Handbook of Sensory Physiology, Vol. VII (Dartnall, H. J. A., ed.), pp. 417-480. Berlin: Springer-Verlag.

Cohen, J. (1988). Statistical Power Analysis for the Behavioural Sciences. Hillsdale, NJ: Lawrence Erlbanm Associates.

Cronly-Dillon, J. R. \& Muntz, W. R. A. (1965). The spectral sensitivity of the goldfish and the clawed toad tadpole under photopic conditions. Journal of Experimental Biology 42, 481-493.

Cummings, M. E. \& Partridge, J. C. (2001). Visual pigments and optical habitats of surfperch (Embiotocidae) in the California kelp forest. Journal of Comparative Physiology A 187, 875-889.

Dartnall, H. J. A. \& Lythgoe, J. N. (1965). The spectral clustering of visual pigments. Vision Research 5, 81-100.

Dartnall, H. J., Lander, M. R. \& Munz, F. W. (1961). Periodic changes in the visual pigments of fishes. In Progress in Photobiology (Christensen, C. \& Buchmann, B., eds), pp. 203-213. Amsterdam: Elsevier.

Douglas, R. H., Partridge, J. C., Dulai, K. S., Hunt, D. M., Mullineaux, C. W. \& Hynninen, P. H. (1999). Enhanced retinal longwave sensitivity using a chlorophyllderived photosensitizer in Malacosteus niger, a deep-sea dragon fish with far-red bioluminescence. Vision Research 39, 2817-2832.

Endler, J. A., Basolo, A. L., Glowacki, S. \& Zerr, J. (2001). Variation in response to artificial selection for spectral sensitivity in guppies, Poecilia reticulata. American Naturalist 158, 36-48.

Fritches, K. A., Partridge, J. C., Pettigrew, J. D. \& Marshall, N. J. (2000). Colour vision in Billfish. Philosophical Transactions of the Royal Society B 355, $1253-1256$.

Gonçalves, E. J., Almada, V. C., Olivera, R. F. \& Santos, A. J. (1996). Female mimicry as a mating tactic in males of the blenniid fish, Salaria pavo. Journal of the Marine Biological Association of the United Kingdom 76, 529-538.

Gonçalves, D., Fagundes, T. \& Oliveira, R. (2003). Reproductive behaviour of sneaker males of the peacock blenny. Journal of Fish Biology 63, 528-532. doi: 10.1046/ j.1095-8649.2003.00157.x.

Govardovskii, V. I., Fyhrquist, N., Reuter, T. \& Kuzmin, D. G. (2000). In search of the visual pigment template. Visual Neuroscience 17, 509-528.

Hart, N. S. (1998). Avian photoreceptors. Ph.D. Thesis, University of Bristol.

Hart, N. S. (2001). The visual ecology of avian photoreceptors. Progress in Retinal and Eye Science 20, 675-703.

Hart, N. S., Partridge, J. C. \& Cuthill, I. C. (1998). Visual pigments, oil droplets and cone photoreceptor distribution in the European starling (Sturnus vulgaris). Journal of Experimental Biology 201, 1433-1446.

Hawryshyn, C. W., Arnold, M. G., Chaisson, D. J. \& Martin, P. C. (1989). The ontogeny of ultraviolet photosensitivity in rainbow trout. Visual Neuroscience 2, 247-254.

Heinermann, P. H. (1984). Yellow intraocular filters in fishes. Experimental Biology 43, $127-147$.

Jacobs, G. H. (1993). The distribution and nature of colour vision among the mammals. Biological Review 68, 413-471.

Jolly, D. W., Mawdesley-Thomas, L. E. \& Bucke, D. (1972). Anesthesia of fish. Veterinary Record 91, 424-426

Kirschfield, K. (1982). Carotenoid pigments: their possible role in protecting against photooxidation in eyes and receptor cells. Proceedings of the Royal Society of London B 216, 71-85. 
Knowles, A. \& Dartnall, H. J. A. (1977). The Photobiology of Vision. New York: Academic Press Inc.

Kondrashev, S. L., Gamburtzeva, A. G., Gnjubkina, V. P., Orlov, O. J. \& My, P. T. (1986). Coloration of corneas in fish. A list of species. Vision Research 26, 287-90.

Kosswig, C. (1967). Tethys and its relation to the peri-Mediterranean faunas of freshwater fishes. Aspects of Tethyran Biogeography, Systematics Association Publication 7, 313-324.

Krauss, A. \& Neumeyer, C. (2003). Wavelength dependence of the optomotor response in zebrafish (Danio rerio). Vision Research 43, 1275-1284.

Levine, J. S. \& MacNichol, E. F. (1979). Visual pigments in teleost fishes: effects of habitat, microhabitat and behavior on visual system evolution. Sensory Processes 3, 95-131.

Levine, J. S. \& MacNichol, E. F. (1985). Microspectrophotometry of primate photoreceptors: art, artefact and analysis. In The Visual System (Fein, A. \& Levine, J. S., ed.), pp. 715-722. New York: Liss.

Liebman, P. A. \& Granda, A. M. (1975). Super dense carotenoid spectra resolved in single cone oil droplets. Nature 253, 370-372.

Loew, E. R. \& Dartnall, H. J. (1976). Vitamin $A_{1} / A_{2}$-based visual pigment mixtures in cones of the rudd. Vision Research 16, 891-896.

Loew, E. R. \& Lythgoe, J. N. (1978). The ecology of cone pigments in teleost fishes. Vision Research 18, 715-722.

Loew, E. R. \& Sillman, A. J. (1993). Age-related changes in the visual pigments of the white sturgeon (Acipenser transmontanus). Canadian Journal of Zoology 71, $1552-1557$.

Loew, E. R. \& Wahl, C. M. (1991) A short-wavelength sensitive mechanism in juvenile yellow perch, Perca flavescens. Vision Research 31, 353-360.

Losey, G. S., McFarland, W. N., Loew, E. R., Zamzow, J. P., Nelson, P. A. \& Marshall, N. J. (2003) Visual biology of Hawaiian coral reef fishes. I. Ocular transmission and visual pigments. Copeia 2003, 433-454.

Lythgoe, J. N. (1972). The adaptation of visual pigments to the photic environment. In Handbook of Sensory Physiology, Vol. VII (Dartnall, H. J. A., ed.), pp. 566-603. New York: Springer-Verlag.

Lythgoe, J. N. (1988). Light and vision in the aquatic environment. In Sensory Biology of Aquatic Animals (Atema, J., ed.), pp. 57-82. Heidelberg: Springer.

Lythgoe, J. N. \& Partridge, J. C. (1989). Visual pigments and the acquisition of visual information. Journal of Experimental Biology 146, 1-20.

Lythgoe, J. N. \& Partridge, J. C. (1991). The modelling of optimal visual pigments of dichromatic teleosts in green coastal waters. Vision Research 31, 361-371.

MacNichol, E. F. J. (1986). A unifying presentation of photopigment spectra. Vision Research 26, 1543-1556.

McDonald, C. G. \& Hawryshyn, C. W. (1995). Intraspecific variation of spectral sensitivity in threespine stickleback (Gasterosteus aculeatus) from different photic regimes. Journal of Comparative Physiology A 176, 255-260.

McFall-Ngai, M., Crescitelli, F., Childress, J. \& Horowitz, J. (1986). Patterns of pigmentation in the eye lens of the deep-sea hatchetfish, Argyropelecus affinis Garman. Journal of Comparative Physiology A 159, 791-800.

McFarland, W. N. \& Munz, F. W. (1975). Part III: The evolution of photopic visual pigments in fishes. Vision Research 15, 1071-1080.

Moreland, J. D. \& Lythgoe, J. N. (1968). Yellow corneas in fish. Vision Research 8, $1377-1380$.

Muntz, W. R. A. (1973). Yellow filters and the absorption of light by the visual pigments of some Amazonian fishes. Vision Research 13, 2235-2254.

Muntz, W. R. \& Mouat, G. S. V. (1984). Annual variations in the visual pigments of brown trout inhabiting lochs providing different light environments. Vision Research 11, 1575-1580.

Munz, F. W. \& McFarland, W. N. (1977). Evolutionary adaptations of fishes to the photic environment. In Handbook of Sensory Physiology, Vol. VII the Visual 
System in Vertebrates (Crescitelli, F., ed.), pp. 193-274. Berlin, Heidelberg, New York: Springer.

Papaconstantinou, C. A. (1979). Secondary sex characters of Blennioid fishes (Pisces: Blenniidae). Thalassografica 1, 57-75.

Parry, J. W. L. \& Bowmaker, J. K. (2000). Visual pigment reconstitution in intact goldfish retina using synthetic retinaldehyde isomers. Vision Research 40, 2242-2247.

Partridge, J. C. (1990). The colour sensitivity and vision in fishes. In Light and Life in the Sea (Herring, P., ed.), pp. 167-184. Cambridge: Cambridge University Press.

Partridge, J. C. \& Cummings, M. E. (1999). Adaptation of visual pigments to the aquatic environment. In Adaptive Mechanisms in the Ecology of Vision (Archer, S. N., Djamoz, M. B. A., Loew, E. R., Partridge, J. C. \& Vallerga, S., eds), pp. 251-284. Dordrecht: Kluwer Academic Publishers.

Partridge, J. C., Shand, J., Archer, S. N., Lythgoe, J. N. \& van Groningen-Luyben, W. A. H. M. (1989). Interspecific variation in the visual pigments of deep-sea fishes. Journal of Comparative Physiology A 164, 513-529.

Patzner, R. A., Seiwald, M., Adlgasser, M. \& Kaurin, G. (1986.). The reproduction of Blennius pavo. V. Reproductive behaviour in the natural environment. Zoologisches Anzeiger 216, 338-350.

Perdices, A., Doadrio, I., Côte, M., Machordom, A., Economidis, P. \& Reynolds, J. D. (2000). Genetic divergence and origin of Mediterranean populations of the river blenny Salaria fluviatilis (Teleostei: Blenniidae). Copeia 2000, 723-731.

Plaut, I. \& Afik, D. (2001). Effect of salinity acclimation on routine activity rate in two closely related species of blennies from different habitats. Israel Journal of Zoology 47, 79-86.

Rapp, L. M., Maple, S. S. \& Choi, J. H. (2000). Lutein and zeaxanthin concentrations in rod outer segment membranes from perifoveal and peripheral human retina. Investigative Ophthalmology and Visual Science 41, 1200-1209.

Roll, B. (2000). Carotenoid and retinoid - two pigments in a gecko eye lens. Comparative Biochemistry and Physiology A 125, 105-112.

Schalch, W. (1992). Carotenoids in the retina - a review of their possible role in preventing or limiting damage caused by light and oxygen. In Free Radicals and Aging (Emerit, I. \& Chance, B., ed.), pp. 280-289. Basel: Birkhauser Verlag.

Schaerer, S. \& Neumeyer, C. (1996). Motion detection in goldfish investigated with the optomotor response is "colour blind". Vision Research 36, 4025-4034.

Shand, J. (1993). Changes in spectral absorption of cone visual pigments during the settlement of the goatfish Upeneus tragula: the loss of red sensitivity as a benthic existence begins. Journal of Comparative Physiology A 173, 115-121.

Shand, J., Partridge, J. C., Archer, S. N., Potts, G. W. \& Lythgoe, J. N. (1988). Spectral absorbance changes in the violet/blue sensitive cones of the juvenile pollack, Pollachius pollachius. Journal of Comparative Physiology A 163, 699-703.

Shand, J., Hart, N. S., Thomas, N. \& Partridge, J. C. (2001). Developmental changes in the visual pigments of black bream, Acanthopagrus butcheri. Investigative Ophthalmology and Visual Science 42, 362-362.

Siebeck, U. E. \& Marshall, N. J. (2000). Transmission of ocular media in labrid fishes. Philosophical Transactions of the Royal Society B 355, 1257-1261.

Snodderly, D. M., Brown, P. K., Delori, F. C. \& Auran, J. D. (1983). The macular pigment. I. Absorbance spectra, localization, and discrimination from other yellow pigments in primate retinas. Investigative Ophthalmology and Visual Science 25, 660-673.

Sommerberg, O., Siems, W. G., Hurst, J. S., Lewis, J. W., Kliger, D. S. \& van Kuijk, F. J. G. M. (1999). Lutein and zeaxanthin are associated with the photoreceptors in the human retina. Current Eye Research 19, 491-495.

Somiya, H. (1982). 'Yellow lens' eyes of the stomiatoid deep sea fish Malacosteus niger. Proceedings of the Royal Society of London B 215, 481-489

Thorpe, A., Douglas, R. H. \& Truscott, R. J. W. (1993). Spectral transmission and shortwave absorbing pigments in the fish lens - I. Phylogenetic distribution and identity. Vision Research 33, 289-300. 
Walls, G. L. \& Judd, H. D. (1933). The intra-ocular colour filters of vertebrates. British Journal of Ophthalmology 14, 641-675, 705-725.

Whitmore, A. \& Bowmaker, J. K. (1989). Seasonal variation in the cone sensitivity and short-wave absorbing visual pigments in the rudd Scardinius erythrophthalmus. Journal of Comparative Physiology A 166, 103-115.

Zander, C. D. (1973). Evolution of Blennioidei in the Mediterranean Sea. Revue des Travaux de l'Institut scientifique des Pêches maritimes 37, 215-221.

Zander, C. D. (1986). Blenniidae. In Fishes of the North-Eastern Atlantic and the Mediterranean, Vol. 3 (Whithead, P. J. P., Bauchot, M. L., Hureau, J. C., Nielsen, J. \& Tortonese, E., eds), pp. 1096-1112. Paris: UNESCO.

Zaunreiter, M., Kotrschal, K., Goldschmid, A. \& Adam, H. (1985). Ecomorphology of the optic system in 5 species of blennies (Teleostei). Fortschritte der Zoologie 30, 731-734

Zigman, S. \& Gilbert, P. W. (1978). Lens colour in sharks. Experimental Eye Research 26, $227-231$. 


\section{Author Query Form}

\section{Journal: Journal of Fish Biology}

\section{Article : 446}

Dear Author,

During the copy-editing of your paper, the following queries arose. Please respond to these by marking up your proofs with the necessary changes/additions. Please write your answers on the query sheet if there is insufficient space on the page proofs. Please write clearly and follow the conventions shown on the attached corrections sheet. If returning the proof by fax do not write too close to the paper's edge. Please remember that illegible mark-ups may delay publication.

Many thanks for your assistance.

Query Query

Remarks

Refs.

1

PE: Shand et al., 1993 has been changed to Shand, 1993 to match the reference list. Please check.

2

PE: Hart, 1998 has not been cited in text. Please check.

3

PE: Please provide the correct page range.

4

PE: The label 'Wavelength (nm)' in $\mathrm{x}$ axis has been added. Please check. 


\section{Please correct and return this set}

Please use the proof correction marks shown below for all alterations and corrections. If you wish to return your proof by fax you should ensure that all amendments are written clearly in dark ink and are made well within the page margins.

\begin{tabular}{|c|c|c|}
\hline Instruction to printer & Textual mark & Marginal mark \\
\hline Leave unchanged & ... under matter to remain & Stet \\
\hline $\begin{array}{l}\text { Insert in text the matter } \\
\text { indicated in the margin }\end{array}$ & $h$ & $\begin{array}{l}\text { New matter followed by } \\
\text { h }\end{array}$ \\
\hline Delete & $\mapsto$ through matter to be deleted & d] \\
\hline Delete and close up & E through matter to be deleted & मी \\
\hline $\begin{array}{l}\text { Substitute character or } \\
\text { substitute part of one or } \\
\text { more word(s) }\end{array}$ & $\begin{array}{l}\text { / through letter or } \mapsto \text { through } \\
\text { word }\end{array}$ & New letter or new word \\
\hline Change to italics & - under matter to be changed & س山 \\
\hline Change to capitals & $\equiv$ under matter to be changed & $\equiv$ \\
\hline Change to small capitals & $=$ under matter to be changed & $=$ \\
\hline Change to bold type & u under matter to be changed & $m$ \\
\hline Change to bold italic & $\bar{\approx}$ under matter to be changed & \\
\hline Change to lower case & Encircle matter to be changed & $\nRightarrow$ \\
\hline Change italic to upright type & (As above) & $\psi$ \\
\hline Insert 'superior' character & $\begin{array}{l}\text { / through character or } \wedge \text { where } \\
\text { required }\end{array}$ & $\begin{array}{l}y \text { under character } \\
\text { e.g. } y\end{array}$ \\
\hline Insert 'inferior' character & (As above) & $L$ over character e.g. $\frac{2}{2}$ \\
\hline Insert full stop & (As above & $\circ$ \\
\hline Insert comma & (As above) & , \\
\hline Insert single quotation marks & (As above) & $y$ and/or $y$ \\
\hline $\begin{array}{l}\text { Insert double quotation } \\
\text { marks }\end{array}$ & (As above) & 'y and/or $y$ \\
\hline Insert hyphen & (As above) & (4y) \\
\hline Start new paragraph & $r$ & $\sqrt{5}$ \\
\hline No new paragraph & 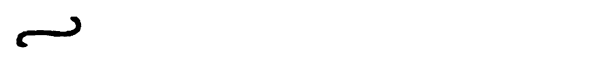 & 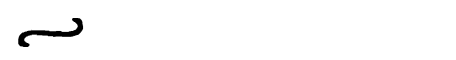 \\
\hline Transpose & $\sqrt{\sim}$ & $\sqrt{-1}$ \\
\hline Close up & linking $\approx$ letters & $=$ \\
\hline Insert space between letters & $\Lambda$ between letters affected & \# \\
\hline Insert space between words & $\boldsymbol{h}$ between words affected & \# \\
\hline Reduce space between letters & $\uparrow$ between letters affected & $T$ \\
\hline Reduce space between words & $\boldsymbol{\top}$ between words affected & \\
\hline
\end{tabular}

